\title{
Article \\ Genetic Manipulation of the Ergot Alkaloid Pathway in Epichloë festucae var. lolii and Its Effect on Black Beetle Feeding Deterrence
}

\author{
Debbie Hudson ${ }^{1}$, Wade Mace ${ }^{1}{ }^{(0)}$, Alison Popay ${ }^{2}{ }^{(}$, Joanne Jensen ${ }^{2}$, Catherine McKenzie ${ }^{1}(\mathbb{D}$, \\ Catherine Cameron ${ }^{2}$ and Richard Johnson $1, * \mathbb{E}$ \\ 1 AgResearch Limited, Grasslands Research Centre, Private Bag 11008, Palmerston North, New Zealand; \\ debbie.hudson@agresearch.co.nz (D.H.); wade.mace@agresearch.co.nz (W.M.); \\ Catherine.McKenzie@plantandfood.co.nz (C.M.) \\ 2 AgResearch Limited, Ruakura Research Centre, Private Bag 3123, Hamilton, New Zealand; \\ alison.popay@agresearch.co.nz (A.P.); joanne.jensen@agresearch.co.nz (J.J.); \\ catherine.cameron2@agresearch.co.nz (C.C.) \\ * Correspondence: Richard.johnson@agresearch.co.nz
}

Citation: Hudson, D.; Mace, W.; Popay, A.; Jensen, J.; McKenzie, C.; Cameron, C.; Johnson, R. Genetic Manipulation of the Ergot Alkaloid Pathway in Epichloë festucae var. lolii and Its Effect on Black Beetle Feeding Deterrence. Toxins 2021, 13, 76. https://doi.org/10.3390/ toxins 13020076

Received: 15 December 2020

Accepted: 15 January 2021

Published: 20 January 2021

Publisher's Note: MDPI stays neutral with regard to jurisdictional claims in published maps and institutional affiliations.

Copyright: (c) 2021 by the authors Licensee MDPI, Basel, Switzerland. This article is an open access article distributed under the terms and conditions of the Creative Commons Attribution (CC BY) license (https:// creativecommons.org/licenses/by/ $4.0 /)$.

\begin{abstract}
Epichloë endophytes are filamentous fungi (family Clavicipitaceae) that live in symbiotic associations with grasses in the sub family Poöideae. In New Zealand, E. festucae var. lolii confers significant resistance to perennial ryegrass (Lolium perenne) against insect and animal herbivory and is an essential component of pastoral agriculture, where ryegrass is a major forage species. The fungus produces in planta a range of bioactive secondary metabolites, including ergovaline, which has demonstrated bioactivity against the important pasture pest black beetle, but can also cause mammalian toxicosis. We genetically modified E. festucae var. lolii strain AR5 to eliminate key enzymatic steps in the ergovaline pathway to determine if intermediate ergot alkaloid compounds can still provide insecticidal benefits in the absence of the toxic end product ergovaline. Four genes ( $d m a W$, eas $G$, cloA, and $l p s B$ ) spanning the pathway were deleted and each deletion mutant was inoculated into five different plant genotypes of perennial ryegrass, which were later harvested for a full chemical analysis of the ergot alkaloid compounds produced. These associations were also used in a black beetle feeding deterrence study. Deterrence was seen with just chanoclavine present, but was cumulative as more intermediate compounds in the pathway were made available. Ergovaline was not detected in any of the deletion associations, indicating that bioactivity towards black beetle can be obtained in the absence of this mammalian toxin.
\end{abstract}

Keywords: Epichlö̈; ergot alkaloid; ergovaline; black beetle; Heteronychus arator; perennial ryegrass; symbiosis; endophyte; secondary metabolite

Key Contribution: Genetic modification of the ergot alkaloid pathway in E. festucae var. lolii demonstrates that bioactivity towards the important pasture pest black beetle (Heteronychus arator) can be obtained in the absence of the mammalian toxin ergovaline, and that feeding deterrence was cumulative as more intermediate compounds in the pathway accumulated.

\section{Introduction}

Epichloë endophytes are filamentous fungi, belonging to the family Clavicipitaceae, which live in symbiotic associations with grasses in the sub family Poöideae [1,2]. In New Zealand, E. festucae var. lolii confers significant resistance to perennial ryegrass (Lolium perenne) against insect and animal herbivory and, as such, is an essential component of pastoral agriculture [3-5], where ryegrass is a major forage species. African black beetle (Heteronychus arator) is an introduced pest in northern New Zealand and is responsible for devasting losses to the pasture industry, costing farmers up to \$242 M annually [6]. A 
number of E. festucae var. lolii strains provide biological control against this serious pest $[7,8]$ through the production of secondary metabolites in planta [9]. Ergovaline, which is the best characterised Epichloë-produced ergot alkaloid [9-13], has demonstrated insecticidal activity against black beetle [14,15], but can also cause mammalian toxicosis [10,12,16,17].

The biosynthetic pathway responsible for ergot alkaloid production has been well characterized from a number of fungi [11,13,18-21], including the ergovaline pathway from Epichloë [9,22]. While the end product of this pathway is ergovaline, intermediate ergot alkaloid compounds are also produced (Figure 1) and the genes responsible for each enzymatic step in the ergovaline pathway have been identified (Figure 1) [9,23,24].<smiles>CC(C)=CCOP(=O)([O-])OP(=O)([O-])O</smiles>
DMAPP
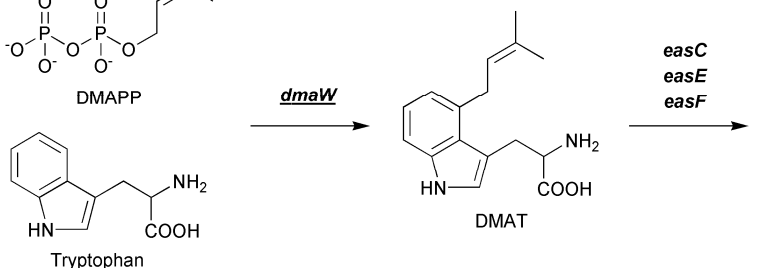

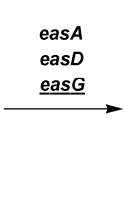

Chanoclavine

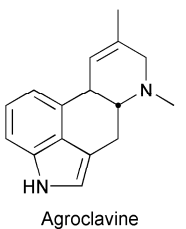

$\underline{\text { cloA }}$

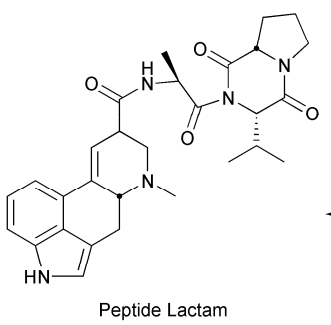

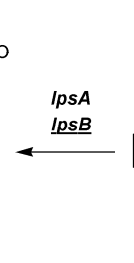

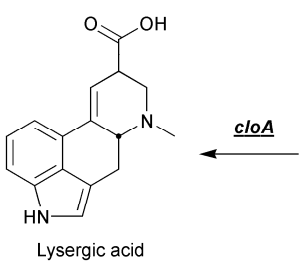

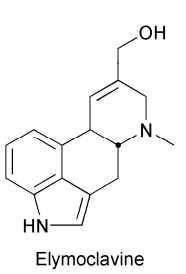

Figure 1. Simplified ergovaline pathway showing pathway intermediates and the key genes proposed for each biosynthetic step. DMAPP = dimethylallyl pyrophosphate, DMAT = dimethylallyl tryptophan. Underlined genes were deleted in this study. Ergovaline (boxed) is a mammalian toxin with bioactivity towards black beetle. A comprehensive review of this pathway is reported in Young et al., 2015 [24].

Functional analysis, through genetic modification, of key genes in this pathway has been achieved for several fungi, including Epichloë, and has provided a detailed understanding of the key biosynthetic steps required for ergot alkaloid biosynthesis $[20,24]$. The gene $d m a W$ encodes dimethylallyl tryptophan synthase, the first enzyme in the ergot alkaloid pathway [25], and as such, deletion of $d m a W$ will lead to the elimination of all ergot alkaloids. The gene eas $G$ encodes an NADPH-dependent reductase involved in converting, via a non-enzymatic adduct with reduced glutathione, the simple ergot alkaloid chanoclavine to agroclavine [26,27]. Deletion of this gene should thus lead to the accumulation of chanoclavine in the absence of other ergot alkaloid compounds. The gene clo $A$ encodes a cytochrome $\mathrm{P} 450$ monooxygenase, which is proposed to be responsible for the oxidation of both agroclavine (to form elymoclavine) and elymoclavine (to form lysergic acid) [28]. Deletion of this gene is thus predicted to lead to the accumulation of chanoclavine and agroclavine in the absence of more complex ergot alkaloids. The genes $\operatorname{lps} A$ and $l p s B$ encode the large and small subunits of a large non-ribosomal peptide synthetase, which is responsible for converting lysergic acid to ergovaline, the last step in the pathway [22,29]. Deletion of either of these genes leads to the accumulation of the clavines group and lysergic acid [22,29].

Despite ergovaline being strongly linked to bioactivity against black beetle [14,15], studies with perennial ryegrass infected with a $\Delta l p s B$ E. festucae mutant surprisingly showed that ergovaline was not required for feeding deterrence [30], suggesting that intermediate ergot alkaloid compounds, or a completely different alkaloid, are responsible. While ergovaline is a known mammalian toxin, the toxicity of the intermediates, and 
whether they also have bioactivity towards black beetle, is less well characterised. In this paper, we describe the outcome of gene deletions in the four key biosynthetic steps (described above) across the ergot alkaloid pathway in E. festucae var. lolii strain AR5. This strain is a commercially utilised (Endo5) Epichloë endophyte of perennial ryegrass [31] that usually produces low to moderate levels of ergovaline, but under adverse conditions, can produce levels that can cause mammalian toxicosis. We used these deletion mutants to engineer Epichlö̈-perennial ryegrass associations expressing a range of different ergot alkaloid compounds in a common host background. These associations were used in a black beetle bioactivity assay to determine whether ergot alkaloid intermediate compounds, such as the clavines or lysergic acid, can contribute to black beetle feeding deterrence in the absence of the mammalian toxin ergovaline.

\section{Results and Discussion}

\subsection{Molecular Screening of Transformants to Identify Gene Deletions in the Ergot Alkaloid Pathway}

E. festucae var. lolii strain AR5 wild type and hygromycin resistant transformants were nuclear purified by sub-culturing three times prior to genomic DNA extraction and screening by polymerase chain reaction (PCR) for each of the ergovaline gene deletion events illustrated in supplementary Figure S1. Transformants showing PCR products of the predicted size (Supplementary Table S1) for a gene deletion event or an ectopic integration, for each of the four ergot alkaloid pathway genes, were inoculated into perennial ryegrass for further analysis.

\subsection{Analysis of Ergot Alkaloids in Gene Deletion Strains}

Perennial ryegrass plants infected with AR5 wild type, two independent transformants corresponding to each of the ergot alkaloid pathway mutants (dmaW KO15 and $\mathrm{KO} 20$, easG KO3 and KO20, cloA KO6 and KO32, and lpsB KO10 and KO11) or ectopic integration controls (dmaW E1, easG E14, cloA E4, and lpsB E9), as well as uninfected plants, were analysed by mass spectrometry for the major ergot alkaloid compounds, in addition to peramine, an unrelated AR5 produced alkaloid that acted as a control for alkaloid production. No endophyte alkaloids were detected in uninfected plants, as expected, and peramine was detected in all endophyte-infected associations, indicating that genetic manipulation of the ergot alkaloid pathway did not otherwise impact secondary metabolism. In addition, all ectopic integrations had chemistry similar to the wild type strain, indicating that the transformation procedure had no impact on secondary metabolism production (Table 1; supplementary Table S2). For each of the AR5 ergot alkaloid pathway genes (Supplementary Table S3) deletions led to differences in the ergot alkaloid profiles detected (Table 1; supplementary Table S2). Deletion of the dmaW gene led to the absence of all ergot alkaloids (Table 1), which was expected given that this gene encodes the first committed step in the ergot alkaloid biosythetic pathway (Figure 1).

Deletion of easG led to the specific accumulation of chanoclavine (at levels similar to that seen in the wild type) in the absence of other ergot alkaloid compounds (Table 1) and fits the proposed biosythetic scheme, in which EasG is involved in the conversion of chanoclavine to agroclavine (Figure 1). The deletion of $c l o A$ led to the accumulation of chanoclavine (at elevated levels relative to the wild type) and agroclavine (at significantly higher levels than to the wild type) in the absence of elymoclavine, which was also not detected in wild type associations (Table 1). The absence of elymoclavine in the wild type associations suggests that this intermediate in the pathway is rapidly converted to lysergic acid, making detection difficult. However, for the $c l o A$ mutant, the absence of elymoclavine and lysergic acid confirms that CloA is likely to perform oxidation of both agroclavine and elymoclavine with the pathway terminating before lysergic acid (Figure 1), as previously proposed [24]. The deletion of $\operatorname{lps} B$ led to a significant accumulation of lysergic acid (Table 1), which is not generally seen in wild type associations. This is similar to results obtained by others who performed earlier gene deletion studies on IpsA [29] and 
lpsB [22], both of which showed significant elevation of lysergic acid. All other earlier ergot alkaloids were detected at levels equivalent to the wild type.

Table 1. Mass spectrometry analysis of ergot and peramine alkaloids from perennial ryegrass infected with gene deletion strains. $\mathrm{WT}=$ wild type, $\mathrm{E}$ Free $=$ uninfected perennial ryegrass. Lysergic acid is relative to ergovaline.

\begin{tabular}{|c|c|c|c|c|c|c|}
\hline & $\begin{array}{l}\text { Chanoclavine } \\
(\mathrm{mg} / \mathrm{kg})\end{array}$ & $\begin{array}{l}\text { Agroclavine } \\
(\mathrm{mg} / \mathrm{kg})\end{array}$ & $\begin{array}{l}\text { Elymoclavine } \\
(\mathrm{mg} / \mathrm{kg})\end{array}$ & $\begin{array}{l}\text { Lysergic Acid } \\
\text { (Relative to Ev) }\end{array}$ & $\begin{array}{l}\text { Ergovaline } \\
\text { (mg/kg) }\end{array}$ & $\begin{array}{c}\text { Peramine } \\
(\mathrm{mg} / \mathrm{kg})\end{array}$ \\
\hline AR5 dmaW KO15 & 0.00 & 0.00 & 0.00 & 0.00 & 0.00 & 29.76 \\
\hline $\mathrm{AR} 5$ dmaW KO20 & 0.00 & 0.00 & 0.00 & 0.00 & 0.00 & 22.60 \\
\hline AR5 easG KO3 & 0.33 & 0.00 & 0.00 & 0.00 & 0.00 & 16.18 \\
\hline AR5 eas G KO20 & 0.69 & 0.00 & 0.00 & 0.00 & 0.00 & 21.38 \\
\hline AR5 cloA KO6 & 0.85 & 0.14 & 0.00 & 0.00 & 0.00 & 22.10 \\
\hline AR5 cloA KO32 & 0.86 & 0.18 & 0.00 & 0.00 & 0.00 & 25.71 \\
\hline AR5 lpsB KO10 & 0.89 & 0.02 & 0.00 & 0.71 & 0.00 & 25.78 \\
\hline AR5 lpsB KO11 & 0.85 & 0.02 & 0.00 & 0.49 & 0.00 & 31.62 \\
\hline AR5 dmaW E1 & 0.77 & 0.03 & 0.00 & 0.00 & 17.42 & 31.59 \\
\hline AR5 eas G E14 & 0.88 & 0.03 & 0.00 & 0.30 & 22.10 & 28.81 \\
\hline AR5 cloA E4 & 0.87 & 0.04 & 0.00 & 0.00 & 13.42 & 27.64 \\
\hline AR5 lpsB E9 & 1.16 & 0.02 & 0.00 & 0.14 & 14.01 & 25.47 \\
\hline AR5 WT & 0.97 & 0.01 & 0.00 & 0.05 & 4.50 & 9.24 \\
\hline E free & 0.00 & 0.00 & 0.00 & 0.00 & 0.00 & 0.00 \\
\hline
\end{tabular}

\subsection{Black Beetle Feeding Deterrence}

The same perennial ryegrass associations described under Section 2.1 for mass spectrometry analysis were also utilised in a black beetle feeding experiment to determine if the altered secondary metabolite profiles of the ergot alkaloid gene deletion mutants had an impact on black beetle feeding. Damaged tillers were scored on a scale of 1-3 (Section 3.8) and the percentage of the total tillers with damage scores of 1, 2, and 3 (low, moderate, or severe damage, respectively) were compared between treatments. Black beetle feeding damage was significantly reduced in plants infected with wild type, all ergot alkaloid pathway deletion mutants, and the ectopic integration strains compared with uninfected perennial ryegrass $(p<0.05)$ (Figure 2$)$. Interestingly, compared with uninfected associations, perennial ryegrass infected with the $d m a W$ deletion mutant showed a significant $(p<0.05)$ reduction in black beetle feeding (Figure 2). As this mutant produces no ergot alkaloids, it suggests that additional unrelated endophyte secondary metabolites have some bioactivity against this pest. E. festucae var. lolii strain AR5 is characterised as producing peramine and early indole diterpenes in addition to ergovaline. However, peramine has been reported to not affect black beetle [14], so this bioactivity is most likely derived from the indole diterpene pathway, or an as yet uncharacterised compound, although it cannot be ruled out that Epichloë infection enhances the host plants' immunity against black beetle by promoting endogenous defense responses mediated by the jasmonic acid (JA) pathway [32].

For the eas $G$ deletion treatments, overall, there was significantly less feeding damage $(p<0.05)$ compared with uninfected perennial ryegrass. However, this level of deterrence, although contributing to an upward trend, was not statistically different to the $d m a W$ mutant, which suggests that chanoclavine, the early ergot alkaloid that solely accumulates in this association (Table 1), has only limited bioactivity against black beetle. This result is corroborated by feeding experiments using purified chanoclavine, which showed no bioactivity against black beetle at the tested concentrations $(2.5,5,10,50$, and $100 \mu \mathrm{g} / \mathrm{g})$ (unpublished results). 


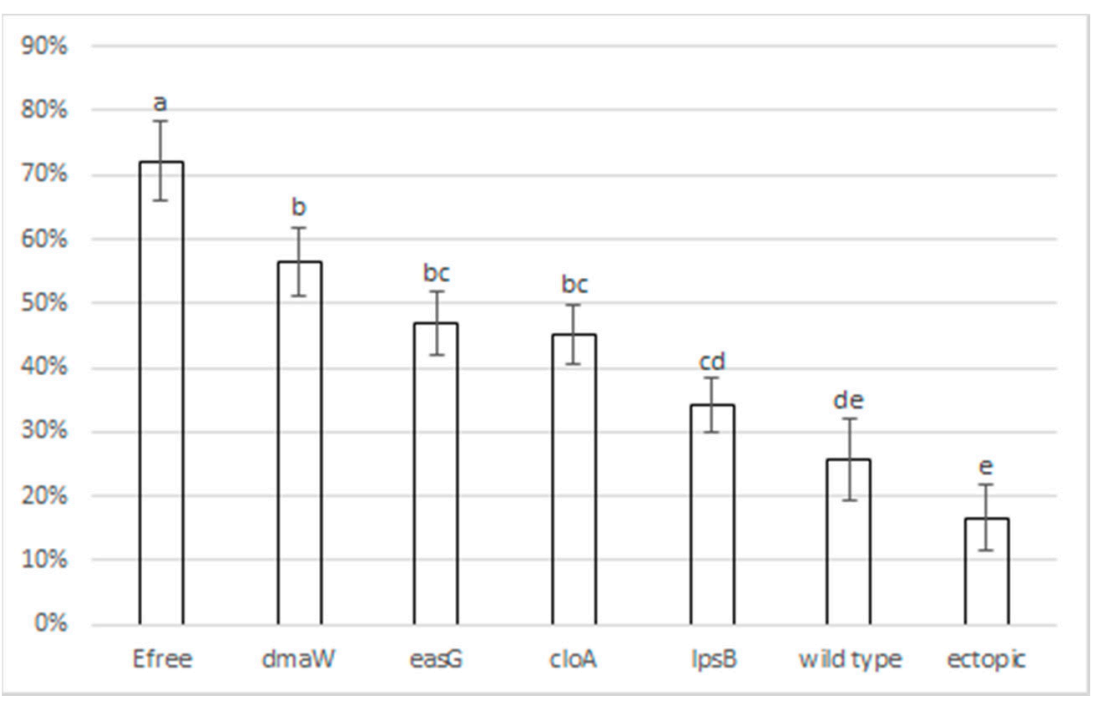

Figure 2. Binary logistic regression analysis of percentage black beetle feeding damage ( $y$-axis) based upon combined scores of 1, 2, and 3 on all tillers for each association. Error bars represent two times the standard error of the estimate from the analysis. Different letters indicate a statistically significant difference $(p<0.05$, least significant difference). Efree $=$ uninfected perennial ryegrass.

For the $c l o A$ deletion treatments, which accumulate agroclavine in addition to chanoclavine, feeding deterrence was similar to the eas $G$ treatments (Figure 2), which suggests that agroclavine, which accumulated significantly in the $c l o A$ mutant associations (Table 1), has little further activity in terms of black beetle feeding deterrence. Despite this, the clavine class of compounds, including agroclavine, have been shown to deter the feeding of fall armyworm (Spodoptera frugiperda) [33] at relatively higher concentrations than those determined here. It is therefore possible that, under certain conditions, such as those in the far north of New Zealand where drought is prevalent, clavines accumulate to higher levels and contribute to some black beetle feeding deterrence in the field.

The $l p s B$ deletion treatments gave the highest levels of black beetle feeding deterrence compared with the wild type (Figure 2), and lysergic acid accumulated to levels not typically seen in wild type associations, suggesting that this compound may contribute significant bioactivity against black beetle.

Wild type associations and ectopic controls showed the greatest deterrence and, taken as a whole, the results from this study imply that bioactivity is cumulative across the entire ergot alkaloid pathway, up to and including ergovaline.

In summary, this research has clearly demonstrated that intermediate compounds in the ergot alkaloid pathway can provide bioactivity against the important pasture pest, black beetle, in the absence of the animal-toxic ergopeptine end product ergovaline. While these intermediate compounds may be less effective in reducing insect damage than ergovaline, this reduction may still offer significant protection to pastures, in the absence of animal toxicity, compared with endophyte free pastures [7]. However, while chanoclavine has been demonstrated to be non-toxic in a mouse assay [34], little information exists about the toxicity of the other clavine species, although agroclavine has been suggested to be cytotoxic at high concentrations [35]. Further studies on the potential toxicity of the clavines and lysergic acid are thus an important step to consider in the utilisation of intermediate ergot alkaloid producing strains in pastures.

\section{Materials and Methods}

\subsection{Bacterial Strains}

Escherichia coli strain Top10 (Invitrogen Corp., Carlsbad, CA, USA) was grown on Luria-Bertani broths and agar plates supplemented with ampicillin $(100 \mu \mathrm{g} / \mathrm{mL})$. 


\subsection{Fungal Strains and Growth Conditions}

Cultures of E. festucae var. lolii AR5 were maintained on 1.5\% $(w / v)$ potato dextrose agar (PDA) (Difco, Sparks, MD, USA) supplemented where necessary with hygromycin $(150 \mu \mathrm{g} / \mathrm{mL})$.

\subsection{Plant Growth and Endophyte Inoculation}

Endophyte-free seedlings of perennial ryegrass (Lolium perenne cv. Samson) were inoculated with E. festucae var. lolii AR5 wild type, ergot alkaloid deletion mutants, and ectopic controls using the method of Latch and Christensen [36]. Twenty plants representing five genotypes with four replicates were used per treatment. Seedlings were grown in proprietary potting mixture in $90 \mathrm{~cm}$ pots under glasshouse conditions for 6 weeks and assessed for endophyte infection by immunoblotting [37].

\subsection{Genomic DNA and Plasmid Isolation}

Genomic DNA was isolated from freeze-dried Epichloë mycelium as previously described [38]. Plasmid DNA was isolated and purified using a plasmid mini kit (Invitrogen).

\subsection{Preparation of Gene Deletion Constructs}

Gene deletion constructs for $d m a W$, eas $G, c l o A$, and $\operatorname{lps} B$ were created by means of MultiSite Gateway cloning (Invitrogen) and utilized a split marker system [39] for improved homologous recombination frequencies. Flanking sequences for each gene were amplified by PCR with attB1- and attB2-tailed primers (Supplementary Figure S1 and Supplementary Table $\mathrm{S} 1$ from E. Festucae var. lolii AR5 genomic DNA. These fragments were recombined into pDONR SML and pDONR SMR vectors using BP clonase (invitrogen). Linear PCR products used for transformation were amplified using PrimeSTAR polymerase (Takara, Shiga, Japan) and primers listed in Supplementary Table S1.

\subsection{Fungal Protoplasting and Transformation}

Protoplasts of E. festucae var. lolii AR5 were prepared as described in Fleetwood et al., 2007 [22]. Fungal cultures were grown in $50 \mathrm{~mL}$ defined media [40] inoculated with macerated fungi (grown on cellophane PDA plates for 7 days at $22^{\circ} \mathrm{C}$ ) and grown at $22{ }^{\circ} \mathrm{C}$ with moderate shaking ( $150 \mathrm{rpm}$ ) for 5 days. The mycelial pellets were washed with $1 \mathrm{~L}$ sterile $\mathrm{H}_{2} \mathrm{O}$ followed by a wash in OM buffer $\left(1.2 \mathrm{M} \mathrm{MgSO}_{4}, 10 \mathrm{mM} \mathrm{Na}_{2} \mathrm{HPO}_{4}\right.$, $\mathrm{pH}$ 5.8). The washed mycelia were mixed with $30 \mathrm{~mL}$ of sterile $\mathrm{OM}$ buffer containing $15 \mathrm{mg} / \mathrm{mL}$ trichoderma lysing enzyme (Sigma, St Louis, MO, USA). This mixture was shaken gently (100 rpm) for $18 \mathrm{~h}$ at $30^{\circ} \mathrm{C}$. The digested hyphae were filtered through Miracloth (Calbiochem, San Diego, CA, USA) and the filtrate, containing the protoplasts, was overlaid with $2 \mathrm{~mL}$ STC buffer ( $0.6 \mathrm{M}$ sorbitol, $100 \mathrm{mM}$ Tris-HCL pH 8.0). The protoplasts were banded at the interface by centrifugation at $3000 \times \mathrm{g}$ for $15 \mathrm{~min}$, washed three times with $10 \mathrm{~mL}$ STC buffer ( $1 \mathrm{M}$ sorbitol, $50 \mathrm{mM} \mathrm{CaCl}_{2}, 50 \mathrm{mM}$ Tris/ $\mathrm{HCl} \mathrm{pH} 8.0$ ) by centrifuging at $7700 \times g$ and resuspended in STC buffer to a final concentration of $1.25 \times 10^{8}$ per mL. Protoplasts were transformed as described in Fleetwood et al., 2007 [22] with $100 \mathrm{fmol}$ linear DNA PCR products for each of the gene deletion constructs. Transformants were selected on RG Media (PD with $0.8 \mathrm{M}$ sucrose $\mathrm{pH}$ 6.5) containing hygromycin $(150 \mu \mathrm{g} / \mathrm{mL}$ ). To obtain clonal isolates, the resulting transformants were purified by sub-culturing three times as described by Young et al., 2005 [41].

\subsection{Molecular Analysis of Transformants}

Transformants were screened by PCR for homologous recombination using primers (Supplementary Table S1) annealed to sequences in the replacement construct on either side of the hygromycin cassette (Supplementary Figure S1 and Table S1). 


\subsection{Black Beetle Insect Feeding Assay}

Plants, confirmed as endophyte-infected by immunoblotting along with uninfected controls, were placed in four replicate blocks in a glasshouse in March (autumn) 2017. Within each block, plants were placed in a row-column design with all treatments to a plant genotype randomized within a row and each column represented by a different plant genotype. Dead tillers and leaf sheath material were removed and plants were trimmed to $50 \mathrm{~mm}$ height and watered with $70 \mathrm{~mL}$ of water. On the same day, one male and one female black beetle that had been collected from pitfall traps set in a Waikato dairy pasture over the previous two weeks were caged onto each individual plant in the first two replicates using a fine nylon net sealed over a wire frame. The following day, beetles were caged onto the remaining two replicates. After two weeks, the cages were removed and herbage was cut from the plants just below ground level. The number of live and dead tillers that were damaged or undamaged by black beetle was recorded. Damaged tillers were scored on a scale of $1-3$, where $1=$ minor surface feeding on the outside of the tiller, $2=$ moderate feeding that had partially penetrated the tiller, and $3=$ severe feeding where the base of the tiller had been shredded and the tiller had wilted. The bottom $40 \mathrm{~mm}$ of tillers from each plant was removed and frozen in liquid nitrogen, and then subsequently freeze-dried for chemical analysis.

Throughout the experiment, plants were each watered with up to $140 \mathrm{~mL}$, as needed.

\subsection{Sample Preparation for Chemical Analysis}

Basal sections of tillers were harvested into liquid nitrogen and then transferred to a freeze-drier. Lyophilized samples were ground and homogenized with a bead ruptor (Omni Bead Ruptor 24, Omni International Inc., Kennesaw, GA, USA) in a $7 \mathrm{~mL}$ vial using a $1 / 4$ inch zirconium bead $(30 \mathrm{~s}$ at $4.5 \mathrm{~m} / \mathrm{s})$.

For analysis, sub-samples $(50 \mathrm{mg})$ were extracted with $1 \mathrm{~mL}$ of extraction solvent $(80 \%$ $\mathrm{v} / \mathrm{v}$ methanol with $0.54 \mathrm{ng} / \mathrm{mL}$ ergotamine, $0.202 \mathrm{ng} / \mathrm{mL}$ festuclavine, and $1.7 \mathrm{ng} / \mathrm{mL}$ homoperamine as internal standard) in $2 \mathrm{~mL}$ plastic vials for $1 \mathrm{~h}$ by end-over-end rotation $(30 \mathrm{~Hz})$ in the dark. After centrifuging $(5000 \times g, 5 \mathrm{~min}), 600 \mu \mathrm{L}$ of the supernatant was further diluted with $3.2 \mathrm{~mL}$ of Milli-Q water (Millipore Australia Pty Ltd, North Ryde, NSW 2113, Australia) before undergoing solid-phase extraction clean-up, as described in Section 3.10. Standards were treated in a similar manner.

\subsection{Solid-Phase Extraction Clean-Up}

The diluted sample extracts were loaded onto pre-conditioned and pre-equilibrated (methanol and water respectively) Strata-X-CW SPE cartridges $(60 \mathrm{mg} / 3 \mathrm{~mL}$ tubes, Phenomenex, Torrance, CA, USA) by centrifuging at $500 \times g$ for $2 \mathrm{~min}$. The cartridges were washed with water $(2 \mathrm{~mL})$ and $50 \%$ methanol $(1 \mathrm{~mL})$ before the target analytes were collected by eluting with $750 \mu \mathrm{L}$ of $5 \%$ formic acid in methanol and $750 \mu \mathrm{L}$ of $1 \%$ ammonia in methanol. The eluents were collected in a high performance liquid chromatography (HPLC) vial and dried by centrifugal evaporation (Speed-Vac Plus SC110A, Savant Instruments Inc., Farmingdale, NY, USA) before resuspending in $200 \mu \mathrm{L}$ of $50 \%$ methanol. Resuspended extracts were stored at $-20^{\circ} \mathrm{C}$ prior to analysis.

\subsection{Analysis for Epichloë Ergot Alkaloids}

Samples $(10 \mu \mathrm{L}$ injection) were chromatographically separated on a Kinetic C18 $150 \times 2.1 \mathrm{~mm}(2.6 \mu \mathrm{m})$ column (Phenomenex, Torrance, CA, USA) using the following linear gradient profile (eluent $\mathrm{A}$, aqueous $0.1 \%$ formic acid and eluent $\mathrm{B}$, acetonitrile with $0.1 \%$ formic acid); time $0 \mathrm{~min}\left(\mathrm{~T}_{0}\right)$ at $10 \% \mathrm{~B}, \mathrm{~T}_{6}$ at $60 \% \mathrm{~B}, \mathrm{~T}_{17}$ at $100 \% \mathrm{~B}$, and $\mathrm{T}_{19}$ at $100 \%$ $\mathrm{B}$, followed by equilibration to initial conditions over the following $8 \mathrm{~min}$. Detection and quantitation were achieved using a triple-quadrupole mass spectrometer (TSQ Quantum, Thermo Fisher Scientific, Waltham, MA, USA) with the following parameters: heated electrospray ionization (HESI) in positive ion mode, capillary temperature $270{ }^{\circ} \mathrm{C}$, sheath 
gas pressure 60, ion sweep gas pressure 10, aux gas pressure 35, and a 0.7 amu window for both Q1 and Q3. Supplementary Table S4 shows the parameters specific to each compound.

\subsection{Data Processing}

The raw data were processed using LCQuan 2.7 (Thermo Fisher Scientific, Waltham, MA, USA). Where internal standards were used, LCQuan was used to determine the final concentration in the samples.

\subsection{Methods of Statistical Analysis}

Statistical analysis was performed with Genstat, 19th edition. The proportion of all tillers showing black beetle damage scores greater than 1 was compared using a regression analysis of binomial data.

Supplementary Materials: The following are available online at https:/ / www.mdpi.com/2072-665 1/13/2/76/s1, Figure S1: Gene deletion by homologous recombination and PCR screening strategy; Table S1: PCR amplicon sizes used to screen transformants for homologous recombination or ectopic insertion events; Table S2: Mass spectrometry raw data; Table S3: E. festucae M3 and E. festucae var. lolii AR5 gene models with AR5 NCBI accession numbers; Table S4: Mass spectrometer parameters for individual compounds.

Author Contributions: Conceptualization, R.J. and A.P.; methodology, D.H., A.P., J.J., W.M.; formal analysis, R.J., A.P., D.H., W.M., C.M. and C.C.; writing-original draft preparation, R.J., D.H. and W.M.; writing-review and editing, R.J., A.P., W.M., J.J.; funding acquisition, R.J., A.P. and W.M. All authors have read and agreed to the published version of the manuscript.

Funding: This research was funded by the New Zealand Strategic Science Investment Fund (SSIF) contract A20067.

Institutional Review Board Statement: Not applicable.

Informed Consent Statement: Not applicable.

Data Availability Statement: Not applicable. Data is provided in the manuscript.

Acknowledgments: We thank Derek Wilson for assistance with black beetle collection and Leo Liu for assistance with chemistry.

Conflicts of Interest: The authors declare no conflict of interest. The funders had no role in the design of the study; in the collection, analyses, or interpretation of data; in the writing of the manuscript; or in the decision to publish the results.

\section{References}

1. Schardl, C.L.; Leuchtmann, A.; Chung, K.-R.; Penny, D.; Siegel, M.R. Coevolution by common descent of fungal symbionts (Epichlö̈ spp.) and grass hosts. Mol. Biol. Evol. 1997, 14, 133-143. [CrossRef]

2. Schardl, C.L. The Epichloae, symbionts of the grass subfamily Poöideae. Ann. Mo. Bot. Gard. 2010, 97, 646-665. [CrossRef]

3. Schardl, C.L.; Phillips, T.D. Protective Grass Endophytes: Where are they from and where are they going? Plant Dis. 1997, 81, 430-438. [CrossRef] [PubMed]

4. Hume, D.E.; Ryan, G.D.; Gibert, A.; Helander, M.; Mirlohi, A.; Sabzalian, M.R. Epichloë fungal endophytes for grassland ecosystems. In Sustainable Agriculture Reviews; Springer: Berlin/Heidelberg, Germany, 2016; pp. 233-305.

5. Johnson, L.J.; de Bonth, A.C.M.; Briggs, L.R.; Caradus, J.R.; Finch, S.C.; Fleetwood, D.J.; Fletcher, L.R.; Hume, D.E.; Johnson, R.D.; Popay, A.J.; et al. The exploitation of epichloae endophytes for agricultural benefit. Fungal Divers. 2013, 60, 171-188. [CrossRef]

6. Ferguson, C.M.; Barratt, B.I.; Bell, N.; Goldson, S.L.; Hardwick, S.; Jackson, M.; Jackson, T.A.; Phillips, C.B.; Popay, A.J.; Rennie, G. Quantifying the economic cost of invertebrate pests to New Zealand's pastoral industry. N. Z. J. Agric. Res. 2019, 62, $255-315$. [CrossRef]

7. Popay, A.; Baltus, J. Black Beetle Damage to Perennial Ryegrass Infected with AR1 Endophyte. In Proceedings of the ConferenceNew Zealand Grassland Association, Hamilton, New Zealand, 30 October-1 November 2001; Volume 63, pp. $267-272$.

8. Popay, A.; Thom, E. Endophyte effects on major insect pests in Waikato dairy pasture. In Proceedings of the New Zealand Grassland Association, Waitangi, New Zealand, 3-5 November 2009; Volume 71, pp. 121-126.

9. Schardl, C.; Young, C.; Hesse, U.; Amyotte, S.; Andreeva, K.; Calie, P.; Fleetwood, D.; Haws, D.; Moore, N.; Oeser, B.; et al. Plant-symbiotic fungi as chemical engineers: Multi-genome analysis of the Clavicipitaceae reveals dynamics of alkaloid loci. PLoS Genet. 2013, 9, e1003323. [CrossRef] 
10. Duringer, J.; DeLorme, M.; Lehner, A.; Craig, A. A review of the ergot alkaloids found in endophyte-infected tall fescue and perennial ryegrass and their metabolism after ingestion by livestock. In Proceedings of the 6th International Symposium on Fungal Endophytes of Grasses, Christchurch, New Zealand, 25-28 March 2007; p. 377382.

11. Gerhards, N.; Neubauer, L.; Tudzynski, P.; Li, S.-M. Biosynthetic pathways of ergot alkaloids. Toxins 2014, 6, 3281-3295. [CrossRef]

12. Guerre, P. Ergot alkaloids produced by endophytic fungi of the genus Epichlö̈. Toxins 2015, 7, 773-790. [CrossRef]

13. Jakubczyk, D.; Cheng, J.Z.; O'Connor, S.E. Biosynthesis of the ergot alkaloids. Nat. Prod. Rep. 2014, 31, 1328-1338. [CrossRef]

14. Ball, O.J.-P.; Miles, C.O.; Prestidge, R.A. Ergopeptine alkaloids and Neotyphodium lolii-mediated resistance in perennial ryegrass against adult Heteronychus arator (Coleoptera: Scarabaeidae). J. Econ. Entomol. 1997, 90, 1382-1391. [CrossRef]

15. Ball, O.-P.; Christensen, M.; Prestidge, R. Effect of selected isolates of Acremonium endophytes on adult black beetle (Heteronychus arator) feeding. In Proceedings of the New Zealand Plant Protection Conference, Waitangi, New Zealand, 9-11 August 1994; Volume 47, pp. 227-231.

16. Fletcher, L. Non-toxic endophytes in ryegrass and their effect on livestock health and production. Ryegrass Endophyte Essent. N. Z. Symbiosis Grassl. Res. Pract. Ser. 1999, 7, 133-139.

17. Klotz, J.; Nicol, A. Ergovaline, an endophytic alkaloid. 1. Animal physiology and metabolism. Anim. Prod. Sci. 2016, 56, 1761-1774. [CrossRef]

18. Wallwey, C.; Li, S.-M. Ergot alkaloids: Structure diversity, biosynthetic gene clusters and functional proof of biosynthetic genes. Nat. Prod. Rep. 2011, 28, 496-510. [CrossRef] [PubMed]

19. Chen, J.-J.; Han, M.-Y.; Gong, T.; Yang, J.-L.; Zhu, P. Recent progress in ergot alkaloid research. RSC Adv. 2017, 7, $27384-27396$. [CrossRef]

20. Coyle, C.M.; Panaccione, D.G. An ergot alkaloid biosynthesis gene and clustered hypothetical genes from Aspergillus fumigatus. Appl. Environ. Microbiol. 2005, 71, 3112-3118. [CrossRef] [PubMed]

21. Panaccione, D.G. Origins and significance of ergot alkaloid diversity in fungi. FEMS Microbiol. Lett. 2005, 251, 9-17. [CrossRef]

22. Fleetwood, D.J.; Scott, B.; Lane, G.A.; Tanaka, A.; Johnson, R.D. A complex ergovaline gene cluster in Epichloë endophytes of grasses. Appl. Environ. Microbiol. 2007, 73, 2571-2579. [CrossRef] [PubMed]

23. Lorenz, N.; Haarmann, T.; Pazoutova, S.; Jung, M.; Tudzynski, P. The ergot alkaloid gene cluster: Functional analyses and evolutionary aspects. Phytochemistry 2009, 70, 1822-1832. [CrossRef]

24. Young, C.A.; Schardl, C.L.; Panaccione, D.G.; Florea, S.; Takach, J.E.; Charlton, N.D.; Moore, N.; Webb, J.S.; Jaromczyk, J. Genetics, genomics and evolution of ergot alkaloid diversity. Toxins 2015, 7, 1273-1302. [CrossRef]

25. Liu, M.; Panaccione, D.G.; Schardl, C.L. Phylogenetic analyses reveal monophyletic origin of the ergot alkaloid gene $d m a W$ in fungi. Evol. Bioinform. 2009, 5, EBO-S2633. [CrossRef]

26. Cheng, J.Z.; Coyle, C.M.; Panaccione, D.G.; O'Connor, S.E. Controlling a structural branch point in ergot alkaloid biosynthesis. J. Am. Chem. Soc. 2010, 132, 12835-12837. [CrossRef] [PubMed]

27. Matuschek, M.; Wallwey, C.; Xie, X.; Li, S.-M. New insights into ergot alkaloid biosynthesis in Claviceps purpurea: An agroclavine synthase EasG catalyses, via a non-enzymatic adduct with reduced glutathione, the conversion of chanoclavine-I aldehyde to agroclavine. Org. Biomol. Chem. 2011, 9, 4328-4335. [CrossRef] [PubMed]

28. Arnold, S.L.; Panaccione, D.G. Biosynthesis of the pharmaceutically important fungal ergot alkaloid dihydrolysergic acid requires a specialized allele of cloA. Appl. Environ. Microbiol. 2017, 83, e00805-e00817. [CrossRef] [PubMed]

29. Panaccione, D.G.; Johnson, R.D.; Wang, J.; Young, C.A.; Damrongkool, P.; Scott, B.; Schardl, C.L. Elimination of ergovaline from a grass-Neotyphodium endophyte symbiosis by genetic modification of the endophyte. Proc. Natl. Acad. Sci. USA 2001, 98, 12820-12825. [CrossRef] [PubMed]

30. Fleetwood, D.J. Molecular Characterisation of the EAS Gene Cluster for Ergot Alkaloid Biosynthesis in Epichloë Endophytes of Grasses: A Thesis Presented in Partial Fulfilment of the Requirements for the Degree of Doctor of Philosophy in Molecular Genetics at Massey University, Palmerston North, New Zealand; Massey University: Palmerston North, New Zealand, 2007.

31. Popay, A.; Hume, D. Endophytes improve ryegrass persistence by controlling insects. Pasture Persistence Grassl. Res. Pract. Ser. 2011, 15, 149-156.

32. Bastias, D.A.; Martínez-Ghersa, M.A.; Ballaré, C.L.; Gundel, P.E. Epichloë fungal endophytes and plant defenses: Not just alkaloids. Trends Plant Sci. 2017, 22, 939-948. [CrossRef]

33. Clay, K.; Cheplick, G.P. Effect of ergot alkaloids from fungal endophyte-infected grasses on fall armyworm (Spodoptera frugiperda). J. Chem. Ecol. 1989, 15, 169-182. [CrossRef]

34. Finch, S.C.; Munday, J.S.; Sprosen, J.M.; Bhattarai, S. Toxicity studies of chanoclavine in mice. Toxins 2019, 11, 249. [CrossRef]

35. Glatt, H.; Eich, E.; Pertz, H.; Becker, C.; Oesch, F. Mutagenicity experiments on agroclavines, new natural antineoplastic compounds. Cancer Res. 1987, 47, 1811-1814. [CrossRef]

36. Latch, G.C.M.; Christensen, M.J. Artificial infection of grasses with endophytes. Ann. Appl. Biol. 1985, 107, 17-24. [CrossRef]

37. Simpson, W.R.; Schmid, J.; Singh, J.; Faville, M.J.; Johnson, R.D. A morphological change in the fungal symbiont Neotyphodium lolii induces dwarfing in its host plant Lolium perenne. Fungal Biol. 2012, 116, 234-240. [CrossRef] [PubMed]

38. Byrd, A.D.; Schardl, C.L.; Songlin, P.J.; Mogen, K.L.; Siegel, M.R. The $\beta$-tubulin gene of Epichloë typhina from perennial ryegrass (Lolium perenne). Curr. Genet. 1990, 18, 347-354. [CrossRef]

39. Rahnama, M.; Forester, N.; Ariyawansa, K.; Voisey, C.; Johnson, L.; Johnson, R.; Fleetwood, D. Efficient targeted mutagenesis in Epichloë festucae using a split marker system. J. Microbiol. Methods 2017, 134, 62-65. [CrossRef] 
40. Kulkarni, R.K.; Nielsen, B.D. Nutritional requirements for growth of a fungus endophyte of tall fescue grass. Mycologia 1986, 78, 781-786. [CrossRef]

41. Young, C.; Bryant, M.; Christensen, M.; Tapper, B.; Bryan, G.; Scott, B. Molecular cloning and genetic analysis of a symbiosisexpressed gene cluster for lolitrem biosynthesis from a mutualistic endophyte of perennial ryegrass. Mol. Genet. Genom. 2005, 274, 13-29. [CrossRef] [PubMed] 